\title{
Preliminary Studies on the Use of Sawdust and Peanut Shell Powder as Adsorbents for Phosphorus Removal from Water
}

\author{
Marian Asantewah Nkansah ${ }^{a^{*}}$, Moses Donkoh a, Osei Akoto a , \\ James Hawkins Ephraim ${ }^{\text {a }}$ \\ ${ }^{a}$ Department of Chemistry, Kwame Nkrumah University of Science and Technology, Kumasi, Ghana
}

\begin{abstract}
Phosphorus is one of the key nutrients that contribute to eutrophication and excess algal growth in rivers, lakes, and other surface water bodies. Such algal blooms affect the lives of aquatic organisms, especially fish, and block sunlight from reaching bottom dwelling plants, thus inhibiting photosynthesis and stunting growth. In this study, sawdust and peanut shell powder were explored as adsorbents for the removal of phosphorus from aqueous solutions. A series of batch experiments were conducted to determine the effects of adsorbent dosage, initial phosphorus concentration, and contact time on the rate of phosphorus removal. The results showed that $78 \%$ and $39 \%$ of phosphorus were removed by sawdust and peanut shell powder, respectively, at adsorbate concentrations of $10 \mathrm{mg} / \mathrm{l}$ (total P) for a period of $180 \mathrm{~min}$ at an adsorbent dosage of $0.4 \mathrm{~g}$. It was also found that the highest phosphorus removal occurred at an adsorbent mass of $0.4 \mathrm{~g}$ of sawdust and $0.6 \mathrm{~g}$ of peanut shell powder. Adsorption data was fitted to the linearised forms of the Freundlich and Langmuir isotherm models to determine the water-adsorbent partitioning coefficient. Sawdust proved to be a better adsorbent than peanut shell powder.
\end{abstract}

Keywords:

Sawdust;

Peanut Shell Powder;

Phosphorus;

Adsorption Isotherm;

Water Treatment.

Article History:

Received: 02 November 2018

Accepted: 24 January 2019

\section{1- Introduction}

According to Kumar and Puri (2012), phosphorus is essential in the metabolism and growth of plants and animals. Though essential, phosphorus in elemental form is toxic and is subject to bioaccumulation. Phosphorus in water exists in two main forms: dissolved (soluble) and particulate (attached to or a component of particulate matter). Orthophosphate is the primary dissolved form of phosphorus and is readily available to algae and other aquatic plants [1].

According to a study conducted by the Minnesota Pollution Control Agency MPCA, (2007), most of the phosphorus discharged by wastewater treatment facilities is in the form of orthophosphate, which is soluble and reactive. The World Health Organization, WHO (2002), has revealed that some of the phosphorus found in soil mineral particles is capable of being converted to soluble phosphorus or settling at the bottom sediment as a result of chemical and physical changes. The study by MPCA (2007) has also indicated that it is only the most tightly bound forms of particulate phosphorus, such as aluminum-bound phosphorus, that are generally not available for algal growth. Due to the propensity of phosphorus to change its form in the environment, most studies usually measure total phosphorus rather than the organic or inorganic form.

Some of the phosphorus found in soil mineral particles is capable of being converted to soluble phosphorus or settling at the bottom of water bodies as a result of chemical and physical changes [2]. A study (WHO, 2002) on the monitoring of bathing waters showed that, under natural conditions, phosphorus is generally scarce in surface water. However, human activities such as increasing nutrient application and the release of effluent such as human waste, industrial waste, household waste, cleaners and detergents, have resulted in excessive loading of phosphorus in rivers and lakes. Water

\footnotetext{
* CONTACT: Maan4gr@yahoo.co.uk

DOI: http://dx.doi.org/10.28991/esj-2019-01166

(C) This is an open access article under the CC-BY license (https://creativecommons.org/licenses/by/4.0/).
} 
quality can be further impaired when bacteria consume dead algae and use up dissolved oxygen, suffocating fish and other aquatic life (IJC 2014).

According to Shock and Pratt (2003), algae blooms also limit recreational use by reducing water clarity and aesthetic qualities [3]. Since phosphorus concentration is crucial and affects the lives of aquatic organisms, there is a need to monitor and remove phosphorus from wastewater before its discharge into the environment. Existing techniques such as chemical precipitation, crystallization, and magnetic separation that are employed for the removal of phosphorus from water can impact on properties such as $\mathrm{pH}$ in addition to being costly [4].

The adsorption technique has been given a lot of attention by scientists nowadays as a method for the treatment of contaminated water and is considered one of the most popular treatment methods applicable in landfill liners to reduce the mobility of contaminants to groundwater $[5,6]$.

In a study conducted by Tu et al. (2016), La-modified clinoptilolite material was successfully used to remove 95\% of phosphorus in a solution. Laterite has also been employed in the removal of phosphorus from sewage, with an 89\% maximum removal [7]. The efficiency of an adsorption process depends upon the nature of adsorbent materials, which should be less costly, readily available and have high uptake capacity [8].

Materials such as activated alumina, iron based compounds, hydroxides, and carbonates, have been used for the treatment of both waste and drinking water [9]. In order to establish the capacity of an adsorbent, adsorption isotherms are plotted. The most common forms of adsorption isotherms used in chemical-environmental studies are the Langmuir, Freundlich and in addition to Brunauer, Emmett and Teller (BET) [10, 11].

The findings of a study conducted on the use of magnetite for phosphorus removal indicated that both Langmuir and Freundlich equations reasonably describe the adsorption of phosphorus, however the maximum adsorption capacity fitted the Langmuir equation [12].

Natural products from agricultural waste, which are generally perceived as low cost, have also been used [13]. In this research, adsorption is employed for the removal of phosphorus from water using sawdust and peanut shell powder as adsorbents. The choice of these materials was based on their availability and low-cost.

\section{2- Materials and Methods}

\section{2-1- Sampling and Sample Preparation}

Sawdust and peanut shell powder were used as adsorbents in this experiment. The sawdust was obtained from the KNUST sawmill and the peanut shells (Arachis hypogaea) from the Ayigya market, Kumasi. Each sample was dried in an oven (Model: $05015-50,115$ volts, 800 watts Cole-Parmer Instrument Company, USA) at a temperature of $105^{\circ} \mathrm{C}$ for $4 \mathrm{~h}$ and ground into a powder using porcelain mortar and pestle. The samples were then sieved using a sieve pore size of $250 \mathrm{pm}$ and stored in sealed containers and labeled prior to analysis.

Prior to sampling, all glassware used were soaked in $10 \% \mathrm{v} / \mathrm{v}$ aqua regia for $24 \mathrm{hr}$ and then rinsed three times with distilled water. It was finally dried in an oven and allowed to cool down before use.

\section{2-2- Preparation of phosphorus Solutions}

All reagents used were of analytical grade. A stock solution of phosphorus was prepared by dissolving $0.044 \mathrm{~g}$ of potassium dihydrogen phosphate (KH2PO4) in the distilled water and transferred into a 200 ml volumetric flask and filled to the mark.

Five standards were prepared from the stock solution by diluting it with distilled water to the desired concentration ( $2 \mathrm{mg} / \mathrm{l}$ to $10 \mathrm{mg} / \mathrm{l}$ ). Phosphorus levels were determined using a spectrophotometric method.

\section{2-3- Preparation of Reagents for Colour Development by the Vanadomolybdophosphoric Acid Method}

- Solution (A) was prepared by dissolving $25 \mathrm{~g}$ of ammonium molybdate in $300 \mathrm{ml}$ distilled water and heated to complete dissolution.

- Solution (B) was prepared by dissolving $1.25 \mathrm{~g}$ of ammonium metavanadate by heating to boiling in $300 \mathrm{ml}$ distilled water. A volume of $330 \mathrm{ml}$ concentrated $\mathrm{HCl}$ was added after cooling.

The resultant solution was transferred into a $1000 \mathrm{ml}$ volumetric flask.

- Solution (A) was carefully poured into solution (B) and mixed well and topped to $1000 \mathrm{ml}$ mark forming Vanadomolydophosphoric acid (combined reagent solution).

An aliquot of $10 \mathrm{ml}$ of the combined reagent solution was measured into the phosphorus solution to be tested and allowed to stay for $15 \mathrm{~min}$ for colour to develop. Phosphorus concentrations were determined by UV-visible spectrophotometer (Shimadzu, UV mini-1240) [14]. 


\section{2-3-1- Adsorption Studies}

In this study, batch adsorption experiments were perfumed at different conditions of concentration, time of interaction and mass of adsorbent. In all cases, $100 \mathrm{ml}$ of solution was used. During each batch of adsorption study, the concentration of phosphorus in solution and on adsorbate was determined before and after the interactions.

\section{2-3-2- Effect of Adsorbent Dosage}

Batch experiments were performed using different masses $(0.1-0.8 \mathrm{~g}$ ) of adsorbent (sawdust and peanut shell powder). Adsorbents were added to $100 \mathrm{ml}$ of $0.5 \mathrm{mg} / \mathrm{l}$ solution of phosphorous at each instance and shaken with an orbital shaker (model; IKA-VIBRAX-VXR, Sigma-Aldrich) for $180 \mathrm{~min}$.

\section{2-3-3- Effect of Contact Time on Rate of Adsorption}

The effect of contact time on the rate of adsorption from solution was studied by varying the time from 30, 60, 120, 180,240 and $300 \mathrm{~min}$. The $\mathrm{pH}$ of the solution $(\mathrm{pH} \mathrm{7})$, the adsorbent dosage $(0.4 \mathrm{~g})$ and the adsorbate concentration $(5$ $\mathrm{mg} / \mathrm{l}$ in $100 \mathrm{ml}$ volumetric flask) were all kept constant. An adsorbate concentration of $5 \mathrm{mg} / \mathrm{l}$ was chosen since it gave the optimum absorption during preliminary trials.

\section{2-3-4- Effect of Adsorbate Concentration and Adsorption Isotherms}

The effect of initial adsorbate concentration on the adsorption was investigated by varying the initial concentration of phosphorus between 2, 4, 6, 8 and $10 \mathrm{mg} / \mathrm{l}$. Adsorbent dosage used for the interaction was $0.4 \mathrm{~g}$, and shaking was done for $180 \mathrm{~min}$.

In order to determine the adsorption capacity of sawdust and peanut shell powder for the removal of phosphorus spiked solutions of concentrations 2, 4, 8 and $10 \mathrm{mg} / 1$ were shaken with $0.4 \mathrm{~g}$ of adsorbent in batch procedures at 180 min (equilibrium time) per batch. The data obtained was fitted to the linearized form of the Langmuir and Freundlich models.

\section{3- Results and Discussion}

The effectiveness of powder from sawdust and peanut shell powder as adsorbents for phosphorus removal from water has been studied. Batch experiments were performed in all the interactions using $100 \mathrm{ml}$ of the specified phosphorus solutions and shaking was done at $220 \mathrm{rpm}$.

\section{3-1- Effect of Adsorbent Dosage on Phosphorus Removal}

The effect of the mass of sawdust and peanut shell powder on phosphorus removal was studied by varying the dose at $0.1,0.2,0.4,0.6$ and $0.8-\mathrm{g} / 100 \mathrm{ml}$ at a fixed adsorbate concentration of $5 \mathrm{mg} / \mathrm{l}(\mathrm{P})$. It was observe that the best adsorbent mass for phosphorus removal occurred at $0.4 \mathrm{~g}$ for sawdust and $0.6 \mathrm{~g}$ for peanut shells (Figure 1).

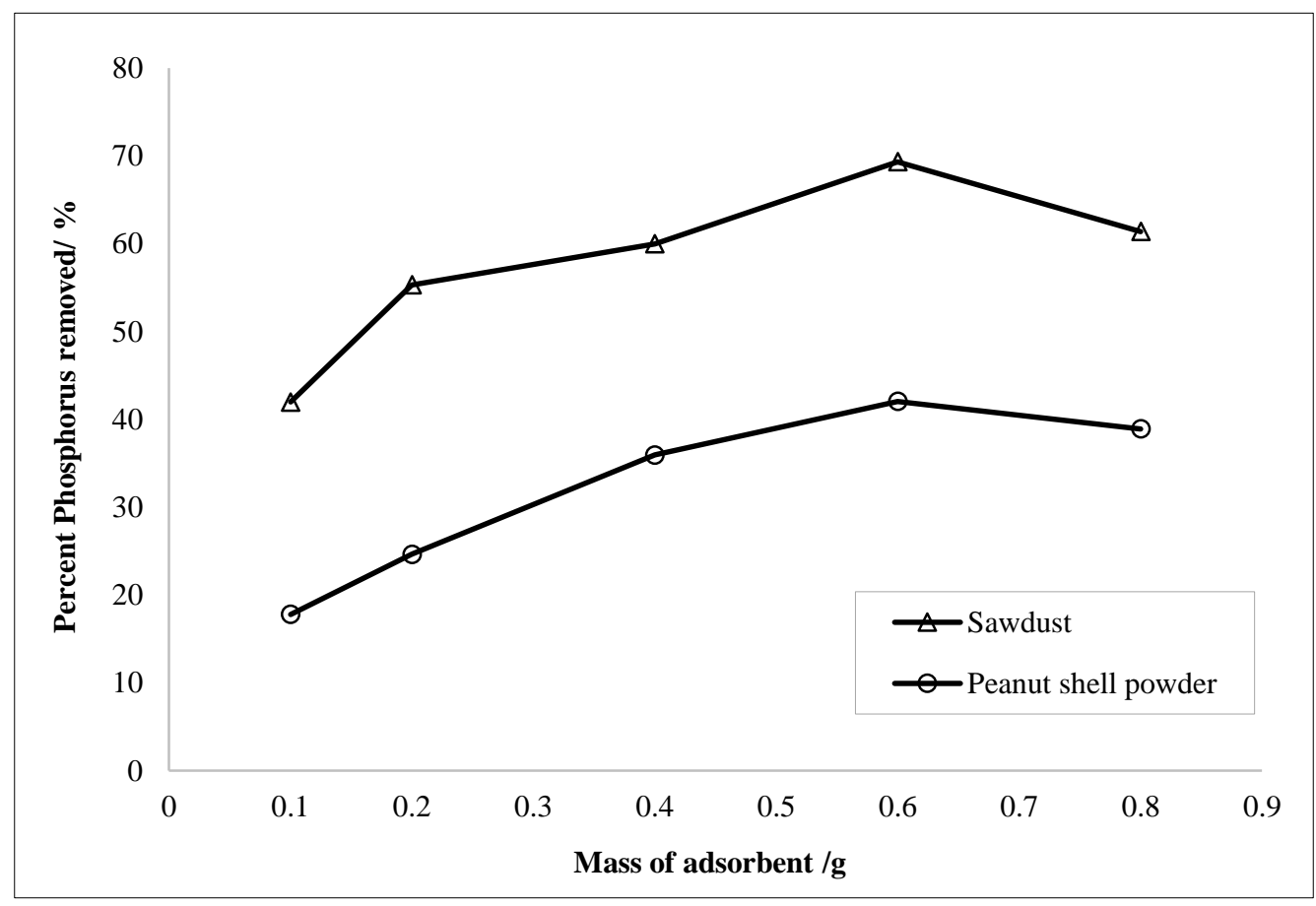

Figure 1. Effect of mass of adsorbent on phosphorus removal 
A plot of percent phosphorus removed versus mass of sawdust used indicated a rise from 41.96 to $69.32 \%$ for 0.1 $0.4 \mathrm{~g}$ respectively. This was followed by a decline with the increase in adsorbent dose. The best mass of sawdust for optimum phosphorus removal was therefore set at $0.4 \mathrm{~g}$. In the case of peanut shell powder, the optimum mass was 0.6 $\mathrm{g}$ giving the highest percent removal at 42.0 (Figure 1). The trend of percent removal increasing with mass of adsorbent to a point and further declining could be due to release of adsorbate back into solution after all the available sites had been covered. The optimum mass for sawdust for phosphorus removal was therefore set at $0.4 \mathrm{~g}$ while that of peanut shell powder was set at $0.6 \mathrm{~g}$. The percentage removal is low when compared to the use of the $85 \%$ removal obtained for a batch experiment which used oven-dried alum sludge dose (50 g/L) for the removal of phosphorus [15].

At higher dosage, the equilibrium uptake of phosphorus ions did not increase significantly with increasing adsorbent dosage. Such behavior is expected due to be due to the saturation level attained during an adsorption process [16].

\section{3-2- Effect of Contact Time on Phosphorus Removal}

The contact time was varied from $30 \mathrm{~min}$ to $300 \mathrm{~min}$. A mass of $0.4 \mathrm{~g}$ of adsorbent was used in each batch experiment for uniformity sake. The percentage removal of phosphorus increased gradually from 30 min up to 300 min at a fixed adsorbate concentration of $5 \mathrm{mg} / \mathrm{l}(\mathrm{P})$. At each time interval of batch experiment, the sawdust adsorbed more of the phosphorus than the peanut shell powder. This indicates that sawdust serves as a better adsorbent than the peanut shell powder. Figure 2 gives the detail description of the interaction. The amount of phosphorus removed after 300 min of interaction was approximately $78 \%$ and $39 \%$ for sawdust and peanut shells respectively (Figure 2). This result could be compared with the results of Baraka et al. 2012 in Cairo (Egypt), where they were able to achieve equilibrium at $60 \mathrm{~min}$ by removing $95 \%$ of phosphorus at an adsorbate concentration of $3 \mathrm{mg} / \mathrm{l}$ (p) using activated Red mud ( $0.1 \mathrm{~g})$. It was also realized that at each time interval, the percent phosphorus removed by sawdust was higher than was removed by peanut shell powder. This implies that nature of adsorbent and the available adsorption sites affect the rate of adsorption of phosphorus. The mechanism of solute transfer to the solid includes diffusion through the fluid film around the adsorbent particle and diffusion through the pores to the internal adsorption sites [17]. In the initial stages of adsorption of phosphate, the concentration gradient between the film and the available pore sites is large, and hence the rate of adsorption is faster.

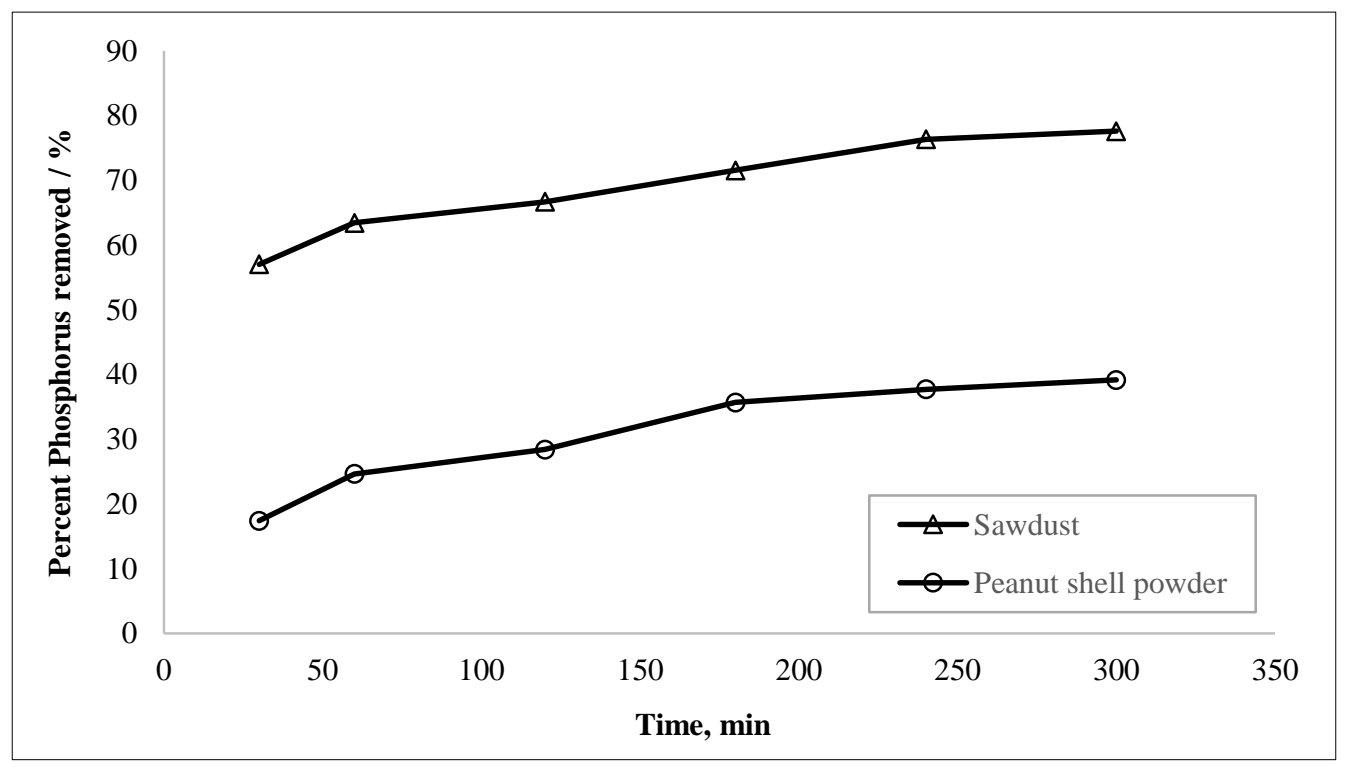

Figure 2. Effect of contact time on phosphorus removal

\section{3-3- Adsorption Isotherms}

In a solid-liquid system interaction, the uptake of solute molecules (phosphorus in this case) consists of the following steps (i) diffusion transport of molecules from the solution to the exterior surface of sorbent through a boundary layer, (ii) intra-particle diffusion of molecules through the interior pores of sorbent and (iii) sorption of molecules onto the active sites on the interior surface $[18,19]$. The graphs plotted in this study used the linear forms of the Freundlich and Langmuir isotherms.

\section{3-3-1- Langmuir Isotherms for Powder from Sawdust and Peanut Shell Powder}

The linear equation for the Langmuir isotherm is given in Equation 1 . Where $C_{e}$ is concentration of phosphorus solution at equilibrium $(\mathrm{mg} / \mathrm{l})$, qe is the amount of phosphorus at equilibrium in unit mass of adsorbent $(\mathrm{mg} / \mathrm{g}), q_{\max }$ and $b$ are the Langmuir coefficient related to adsorption capacity $(\mathrm{mg} / \mathrm{g})$ and adsorption energy respectively [11]. 
$C_{e} / q_{e}=1 / b . q_{\max }+\left(1 / q_{\max }\right) C_{e}$

A plot of $C_{e} / q_{e}$ versus $C_{e}$ s gives a straight line. $q_{\max }$ and $b$ values are obtained from the slope and intercept of the straight line.

The Langmuir isotherms for sawdust and peanut shell powder are presented in Figures 3 and 4 respectively.

The Langmuir isotherm is used to obtain a maximum adsorption capacity produced by complete monolayer coverage of the adsorbent surface. The Langmuir adsorption isotherms were determined for phosphorus at concentrations ranging from 2 to $10 \mathrm{mg} / \mathrm{l}$.

The Langmuir constant $q_{\text {max }}$, which is a measure of the monolayer adsorption capacity was - $0.198 \mathrm{mg} / \mathrm{g}$ for sawdust and that of peanut shell powder was $-0.256 \mathrm{mg} / \mathrm{g}$. The Langmuir constant, $b$ which denotes adsorption energy for sawdust and peanut shell powder were found to be $-0.429 \mathrm{~L} / \mathrm{mg}$ and $-0.201 \mathrm{~L} / \mathrm{mg}$ respectively. The negative values for the Langmuir isotherm constants indicate the inadequacy of the isotherm model to explain the adsorption process. This is confirmed in a study by Al-Anber (2011) [20].

A reverse situation was observed for a study of activated alumina in the removal of phosphorus in which confirmed the Langmuir model [21].

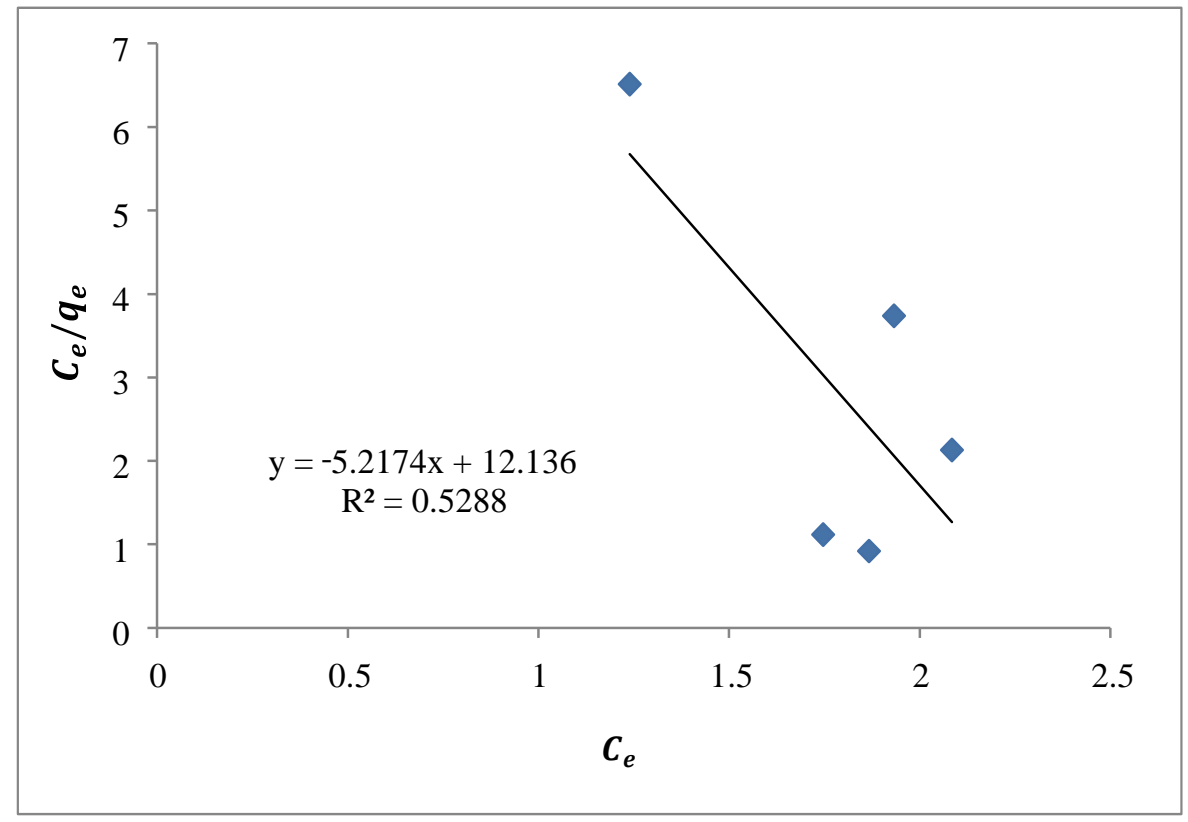

Figure 3. Langmuir isotherm for sawdust

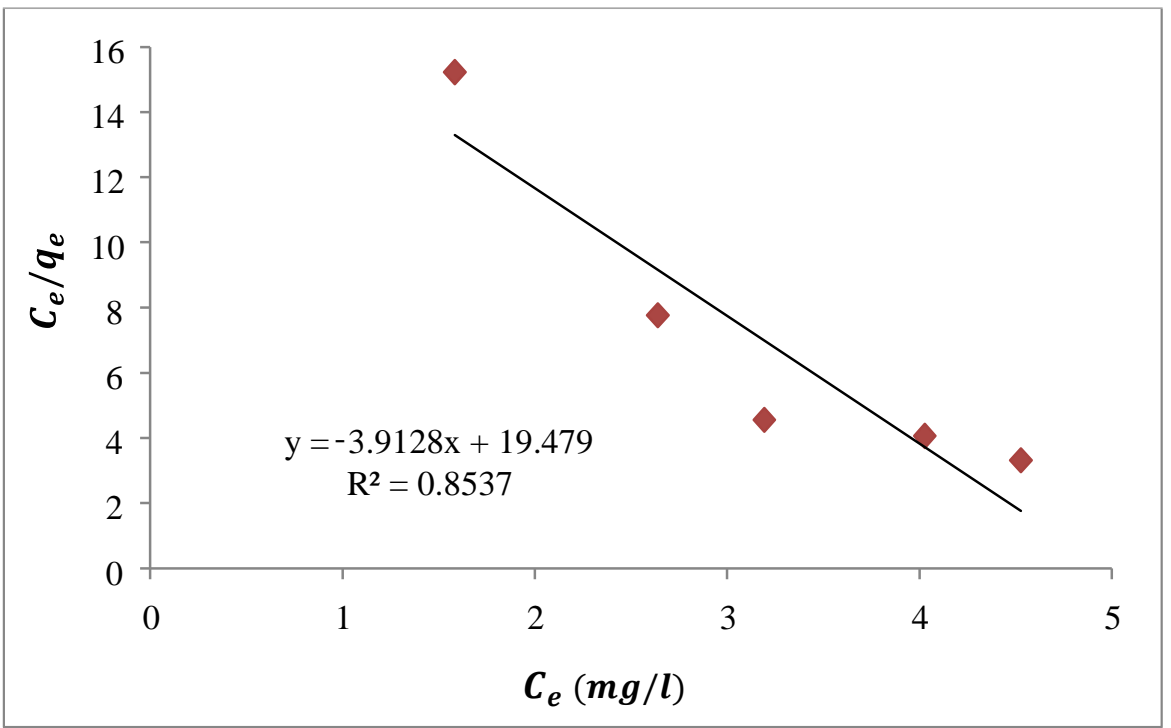

Figure 4. Langmuir isotherm for peanut shell powder 


\section{3-3-1- Freundlich Isotherm for Powder from Sawdust and Peanut Shell Powder}

The linear form of the Freundlich isotherm is given in Equation 2. Where q is mass of adsorbed pollutant per unit of sorbent $(\mathrm{mg} / \mathrm{g}), \mathrm{Cw}(\mathrm{mg} / \mathrm{L})$ is the dissolved phosphorus in water, $\mathrm{n}$ is the measure of linearity and Kf is Freundlich constant. The values of $\mathrm{Kf}$ and $1 / \mathrm{n}$ are obtained from the intercept and slope of the plot of $\log \mathrm{q}$ versus $\log \mathrm{Cw}$. Kf is related to the sorption capacity while $\mathrm{n}$ is related to the sorption intensity [10].

The Freundlich constants, Kf and $\mathrm{n}$ were obtained by plotting the graph of log qe versus log Ce as shown in Figures 5 and 6. Freundlich parameters (Kf and $\mathrm{n}$ ) indicate whether the nature of sorption is either favorable or unfavorable i.e. Whether the adsorption mechanism is heterogeneous or monolayer.

The intercept $\mathrm{Kf}$ is an indicator of sorption capacity and the slope $1 / n$ is an indicator of sorption strength and a measure of the deviation from linearity of the adsorption. The steeper the isotherm, the more effective is the adsorbent. Smaller values of $n<1$ mean that, sorption intensity is good or (favourable) at high concentrations but much less at lower concentrations [17]. The constants $\mathrm{n}$ and $\mathrm{Kf}$ for sawdust were 0.30 and 0.12 respectively and those for peanut shell powder were 0.4058 and 0.034 respectively. All the Freundlich constants obtained for sawdust and peanut shell powder in this study are positive.

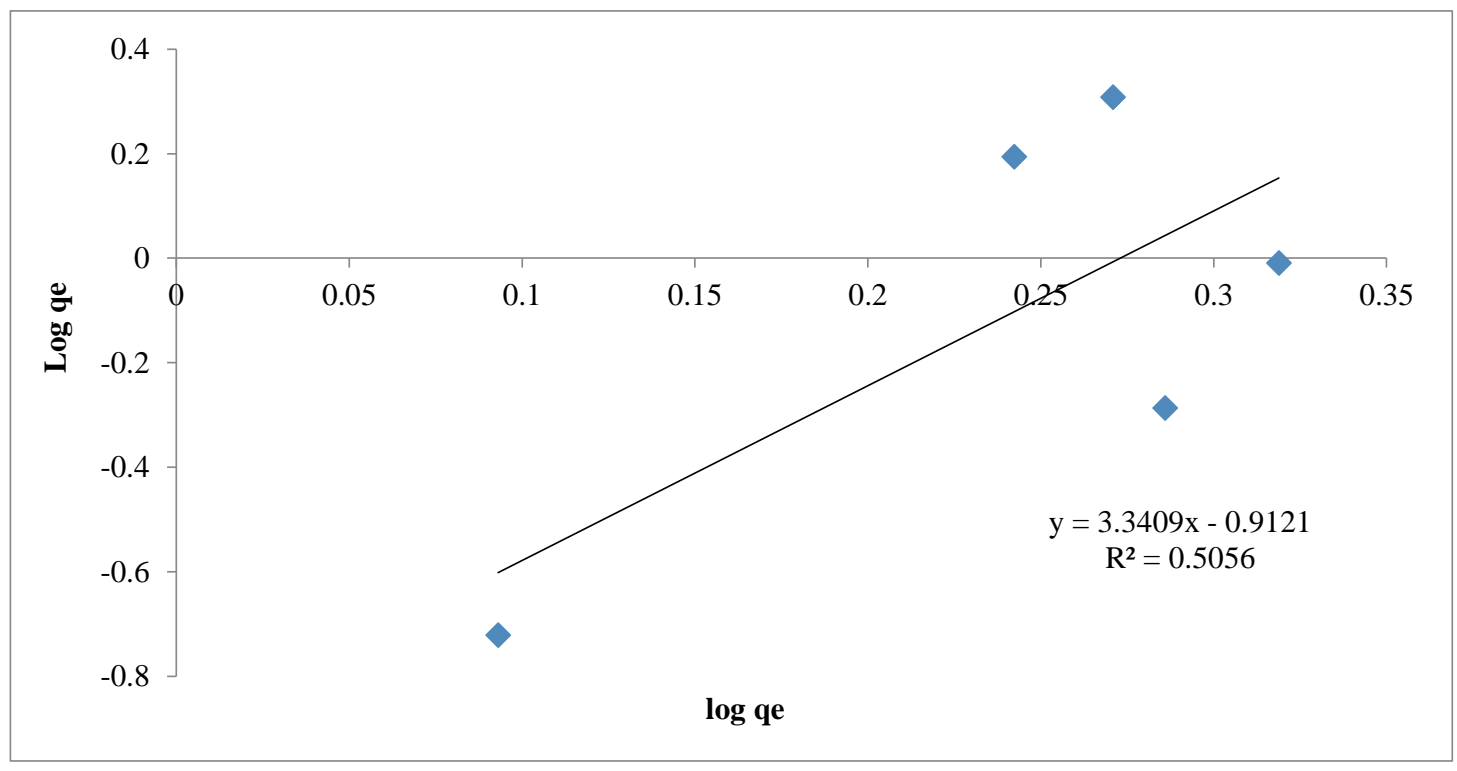

Figure 5. Freundlich isotherm for sawdust

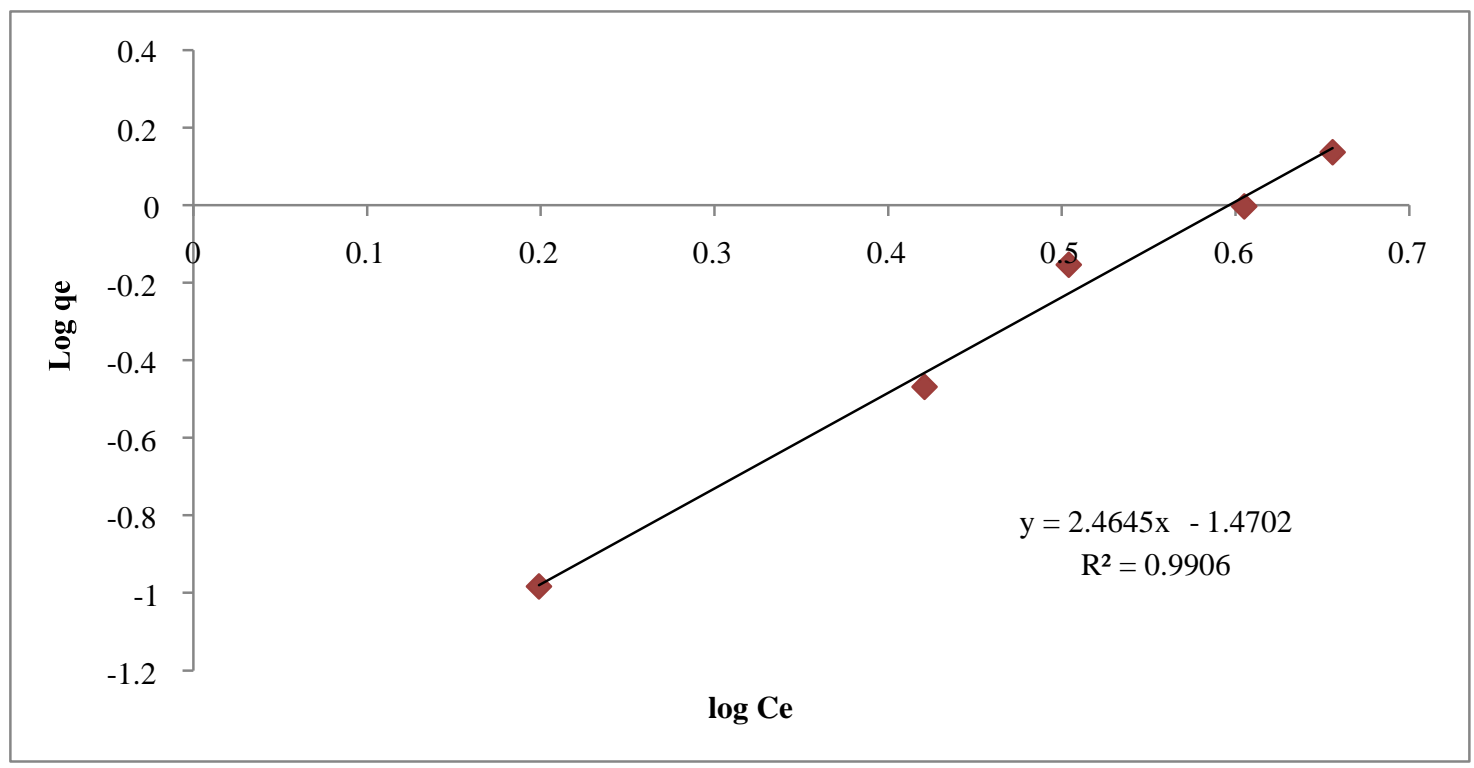

Figure 6. Freundlich isotherm peanut shell powder 
Adsorbents with n values near 1.0 are valid for many organic contaminants while lower values (0.3-0.6) are valid for heavy metals and phosphorus [22]. The constants obtained here is an indication that these materials (sawdust and peanut shell powder) could be good sorbents for phosphorus. The better fitness of the Freundlich model compared to Langmuir's model confirms the heterogeneous nature of adsorbent surfaces.

$$
\log q=\log K f+1 / n \log C_{w}
$$

\section{4- Conclusions}

From the analysis carried out, the following conclusions resulted:

- Sawdust has a much higher adsorption capacity than peanut shell powder for phosphorus removal from water.

- The amount of phosphorus removed after $300 \mathrm{~min}$ of interaction was approximately $78 \%$ and $39 \%$ for $0.4 \mathrm{~g}$ of sawdust and $0.4 \mathrm{~g}$ of peanut shell powder, respectively.

- The equilibrium time for phosphorus ions was not obtained for either adsorbent during the analysis, but adsorbent dosage for sawdust and peanut shell powder was achieved at $0.4 \mathrm{~g}$ and $0.6 \mathrm{~g}$, respectively.

- The adsorption process is strongly affected by parameters such as adsorbent dosage, contact time, adsorbate concentration, etc.

- The adsorption isotherms following the Freundlich model predict the heterogeneous nature of the adsorption.

It is recommended that the adsorbents be tried on polluted waters in the real environment to check their applicability and that the method be developed further to ascertain the equilibrium time and the possibility of regeneration of adsorbents.

\section{5- Acknowledgments}

The researchers are grateful to the Department of Chemistry of the Kwame Nkrumah University of Science and Technology for the use of its facilities for this study.

\section{6- Conflict of Interest}

The authors declare no conflict of interest.

\section{7- References}

[1] Puri, Avinash, and Manoj Kumar. "A Review of Permissible Limits of Drinking Water." Indian Journal of Occupational and Environmental Medicine 16, no. 1 (2012): 40. doi:10.4103/0019-5278.99696.

[2] Government of Western Australia (GWA) (2005) "Nitrogen and Phosphorus Cycles". River Science. 4: 41-8.

[3] Shock, Clinton C., Kathy Pratt, and M. E. Station. "Phosphorus effects on surface water quality and phosphorus TMDL development." In Western nutrient management conference, vol. 5, no. 21, p. 1. 2003.

[4] Gray, N. F. "An introduction for environmental scientists and engineers." Water Technology. Butterworth-Heinemann, Oxford, United Kingdom (2000).

[5] Ramakrishnaiah, C. R. "Vismitha (2012) Removal of Phosphate from Waste Water Using Low-Cost Adsorbents." International Journal of Engineering Inventions 1, no. 7: 44-50.

[6] Sunil, B.M., and Saifiya Faziludeen. "Removal of Hexavalent Chromium Cr (VI) by Adsorption in Blended Lateritic Soil." Advances in Environmental Research 4, no. 3 (September 25, 2015): 197-210. doi:10.12989/aer.2015.4.3.197.

[7] Patil Mansing, R., and P. D. Raut. "Removal of phosphorus from sewage effluent by adsorption on Laterite." International Journal of Engineering Research \& Technology (IJERT) (2013): 2278-0181.

[8] Rout, Prangya Ranjan, Puspendu Bhunia, and Rajesh Roshan Dash. "A Mechanistic Approach to Evaluate the Effectiveness of Red Soil as a Natural Adsorbent for Phosphate Removal from Wastewater.” Desalination and Water Treatment 54, no. 2 (January 24, 2014): 358-373. doi:10.1080/19443994.2014.881752.

[9] Jeffrey Yang, Y., Roy C. Haught, and James A. Goodrich. "Real-Time Contaminant Detection and Classification in a Drinking Water Pipe Using Conventional Water Quality Sensors: Techniques and Experimental Results." Journal of Environmental Management 90, no. 8 (June 2009): 2494-2506. doi:10.1016/j.jenvman.2009.01.021.

[10] Freundlich, H. M. F. "Over the adsorption in solution." The Journal of Physical Chemistry A, 57, no. 385471 (1906): $1100-1107$. 
[11] Langmuir, Irving. "Adsorption of gases by solids." Journal of the American Chemical Society 38, no. 10 (1916): 2267.

[12] Xiang, Heng, Chaoxiang Liu, Ruiling Pan, Yun Han, and Jing Cao. "Magnetite for Phosphorus Removal in Low Concentration Phosphorus-Contained Water Body." Advances in Environmental Research 3, no. 2 (June 25, 2014 ): $163-172$. doi:10.12989/aer.2014.3.2.163.

[13] Gautam, Ravindra Kumar, Sushmita Banerjee, Pavan Kumar Gautam, and M. C. Chattopadhyaya. "Remediation technologies for phosphate removal from wastewater: an overview." Advances in Environmental Research 36 (2014): 177-200.

[14] Eaton, AD., Clesceri L.S., Rice E.W., Greenberg A.E., Franson M.H. Eds.,"Standard Methods for the Examination of Water and Wastewater: 21 st ed."; American Public Health Association: Washington, DC, Water Environment Federation: Alexandria, VA, and American Water Works Association: Denver, CO, (2005).

[15] Mohammed, Wadood T., and Sarmad A. Rashid. "Phosphorus Removal from Wastewater Using Oven-Dried Alum Sludge." International Journal of Chemical Engineering 2012 (2012): 1-11. doi:10.1155/2012/125296.

[16] Ragheb, Safaa M. "Phosphate Removal from Aqueous Solution Using Slag and Fly Ash." HBRC Journal 9, no. 3 (December 2013): 270-275. doi:10.1016/j.hbrcj.2013.08.005.

[17] Baraka, A. M., Marwa M. El-Tayieb, M. El Shafai, and Nouran Yussri Mohamed. "Sorptive removal of phosphate from wastewater using activated red mud." Australian Journal of Basic and Applied Sciences 6 (2012): 500-510.

[18] Ranjbar, Ali, and Najmeh Mahjouri. "Development of an Efficient Surrogate Model Based on Aquifer Dimensions to Prevent Seawater Intrusion in Anisotropic Coastal Aquifers, Case Study: The Qom Aquifer in Iran.” Environmental Earth Sciences 77, no. 11 (June 2018). doi:10.1007/s12665-018-7592-2.

[19] Yuan, Ye, Fuxing Sun, Hao Ren, Xiaofei Jing, Wei Wang, Heping Ma, Huijun Zhao, and Guangshan Zhu. "Targeted Synthesis of a Porous Aromatic Framework with a High Adsorption Capacity for Organic Molecules." Journal of Materials Chemistry 21, no. 35 (2011): 13498. doi:10.1039/c1jm11998b.

[20] Al-Anber, Mohammed A. "Thermodynamics approach in the adsorption of heavy metals." In Thermodynamics-Interaction Studies-Solids, Liquids and Gases. IntechOpen, 2011. ISBN: 978-953-307-563-1.

[21] Wang, Junling, Yajun Zhang, Cuimin Feng, Junqi LI, and Guibai LI. “Adsorption Capacity for Phosphorus Comparison among Activated Alumina, Silica Sand and Anthracite Coal.” Journal of Water Resource and Protection 01, no. 04 (2009): $260-264$. doi:10.4236/jwarp.2009.14031.

[22] Ansari R., Zanjanchi MA., Mohammadkhah A., Mosayebzadeh Z. "Removal of basic dyes from textile wastewaters using sawdust", 7th National Conference on Textile Engineering, Rasht, Iran, (2009). 